\title{
Estado da questão sobre a formação inicial de professores para o ensino de Física Moderna e Contemporânea
}

João Pedro Quaresma Castro Salomão ${ }^{1}$

Mestrando no Programa de Pós-Graduação em Educação em Ciências da Universidade Federal do Rio Grande

Rafaele Rodrigues de Araujo ${ }^{1}$

Universidade Federal do Rio Grande

Rio Grande - RS

\section{Resumo}

O presente trabalho apresenta o estado da questão sobre a formação inicial de professores para introdução de Física Moderna e Contemporânea no Ensino Médio. A investigação ocorreu na emergência de 14 artigos advindos da seleção em periódicos classificados como A1 e A2 pelo Qualis CAPES na área do Ensino, do Simpósio Nacional em Ensino de Física e do Encontro de Pesquisa em Ensino de Física, dos últimos 10 anos. Com a análise realizada encontramos duas categorias emergentes: "Racionalidade técnica como prática do professor formador: consequências para a introdução de Física Moderna e Contemporânea no Ensino Médio" e "Formação inicial de professores para a introdução de Física Moderna e Contemporânea no Ensino Médio: A interação, o diálogo e a pesquisa como pilares da prática do professor formador". Diante das discussões realizadas argumentamos que a interação, o diálogo e a investigação como princípios de ensino do professor formador, possibilitam a inserção da Física Moderna e Contemporânea no Ensino Médio.

Palavras-chave: Formação Docente; Física Moderna e Contemporânea; Ensino Médio; Estado da questão.

\footnotetext{
${ }^{+}$The status of the question on initial teacher training for the Modern and Contemporary Physics teaching

* Recebido: abril de 2020. Aceito: julho de 2020.

${ }^{1}$ E-mails: jowbalbi@hotmail.com; rafaelearaujo@furg.br
} 


\begin{abstract}
This work presents the status of the question on the teachers' initial formation for the introduction of Modern and Contemporary Physics in High School. The research involved 14 articles selected in the last 10 years from journals classified as A1 and A2 by Qualis CAPES in the area of Education and of the National Symposium on Physics Teaching and Research Meeting on Physics Teaching. With the analysis carried out, we found two emerging categories: "Technical rationality as practice of the trainer teacher: consequences for the introduction of Modern and Contemporary Physics in High School" and "Initial teacher training for the Modern and Contemporary Physics in High School introduction: Interaction, dialogue and research as pillars of the trainer teacher". In view of the discussions performed, we argue that interaction, dialogue, and research as teaching principles of the teacher trainer allow the insertion of Modern and Contemporary Physics in High School.
\end{abstract}

Keywords: Teacher Training; Modern and Contemporary Physics; High School; State of the Question.

\title{
I. Introdução
}

Atualmente várias são as discussões sobre o impacto que a ciência tem em nossas vidas, seja diretamente através de aparelhos tecnológicos que estão à nossa volta, ou indiretamente através de suas manifestações nos campos político, econômico, cultural, ambiental e social. As influências que a ciência sofre e o poder que ela exerce, através dos avanços tecnológicos, acabam por direcionar os rumos de uma sociedade, e fazem com que se torne um dos temas centrais quando falamos de uma educação voltada para a formação de um cidadão capaz de compreender e atuar no mundo em que vivemos hoje.

Na promoção de uma educação científica significativa e emancipatória, Terrazan (1994), Pereira e Ostermann (2009) mostram que a Física, em especial a Física Moderna e Contemporânea (FMC), contempla amplamente um processo de ensino e aprendizagem que viabiliza o progresso educacional desejado, estimulando e oferecendo ferramentas necessárias para uma formação libertadora. Porém, a não obrigatoriedade da FMC no Ensino Médio, segundo a Matriz Curricular do Exame Nacional do Ensino Médio (ENEM) ou segundo a Base Nacional Curricular Comum (BNCC) auxilia no distanciamento desses conteúdos na rede de ensino pública.

Entendendo a importância da introdução da FMC no Ensino Médio, os pesquisadores na área do ensino de Física estão desenvolvendo e aplicando metodologias que possibilitem o 
ensino e aprendizagem da mesma. Conforme Pereira e Ostermann (2009) em sua revisão bibliográfica acerca do tema, entre as abordagens mais trabalhadas pelos pesquisadores estão o uso de Tecnologias de Informação e Comunicação (TIC); a abordagem Ciência, Tecnologia e Sociedade (CTS); e a articulação com a História e a Filosofia da Ciência (HFC).

Nesse cenário, percebemos o potencial pedagógico que a FMC tem ao possibilitar o contato do aluno com: conhecimentos responsáveis pelo entendimento de aparatos tecnológicos do dia a dia, compreensão do seu impacto em relação aos avanços tecnológicos, percepção de como se constrói o conhecimento científico, além da possibilidade de instigar os estudantes pela disciplina de Física e por carreiras cientificas. No entanto, se percebe, através do trabalho de Monteiro, Nardi e Bastos Filho (2009) que a FMC não está chegando de fato às escolas, ou seja, as pesquisas não estão surtindo o efeito esperado. Nessa perspectiva, ressaltamos que um dos pontos a ser considerado é que o desenvolvimento de metodologias, de forma isolada, não se mostra suficiente para introduzir esse conteúdo. Para que essas metodologias tenham êxito, precisamos considerar agentes externos a ela como, os materiais didáticos disponíveis na rede, as abordagens e perspectivas teóricas de aprendizagem utilizadas, o currículo das escolas e principalmente a formação de professores.

Dentre esses pontos citados consideramos o papel do professor indispensável nesse processo de introdução da FMC no Ensino Médio, uma vez que ele é o principal agente responsável por mediar esse conhecimento dentro de sala de aula. A participação consciente e ativa do professor é de suma importância, independentemente da existência ou não de outros fatores externos, para que consigamos levar essa Física para a escola. Terrazzan (1992) já destacou há um certo tempo a necessidade de introduzir esse conteúdo no Ensino Médio, alertando também sobre a participação do professor nesse processo.

\begin{abstract}
A influência crescente dos conteúdos de Física Moderna e Contemporânea para o entendimento do mundo criado pelo homem atual, bem como a inserção consciente, participativa e modificadora do cidadão neste mesmo mundo, define, por si só, a necessidade de debatermos e estabelecermos as formas de abordar tais conteúdos na escola de $2^{\circ}$ grau. Não podemos, no entanto, nós professores e pesquisadores da Universidade, enfrentarmos tal tarefa sem a participação conjunta daqueles que praticam a física escolar secundária: os professores de fisica do $2^{\circ}$ grau (TERRAZZAN, 1992, p. 210).
\end{abstract}

Percebemos a necessidade de um olhar mais atento para a formação inicial de professores para introdução de FMC no Ensino Médio se o que pretendemos é contribuir com uma educação científica, que possibilite de fato um ensino democrático, em que todos possam, desde cedo, compreender o que é, e como se constrói essa ciência. Assumimos o fato de que o conteúdo de FMC tem suas especificidades que dificultam a sua introdução na Educação Básica, como o caráter matematizado, a falta de materiais didáticos, sua não obrigatoriedade, entre outros. 
Dessa forma, frisamos a importância da formação do professor para que esse conteúdo chegue da melhor forma até os estudantes do Ensino Médio. Tendo como objetivo auxiliar pesquisas futuras com o entendimento e a compreensão da demanda do cenário atual da formação de professores para introdução de FMC no Ensino Médio, questionamos: o que é isso que se mostra de produções e discussões da comunidade científica brasileira sobre o tema formação inicial de professores em relação à Física Moderna e Contemporânea. Sendo assim, a organização da escrita ocorrerá, primeiramente, mostrando o percurso metodológico realizado, ou seja, o Estado da Questão. Posteriormente, traçaremos como foi feita a análise dos artigos emergentes, quais foram os movimentos realizados e que nos possibilitaram discutir aspectos importantes do cenário atual de formação inicial de professores para introdução de FMC no Ensino Médio. Finalizaremos com a discussão das categorias finais, explicitando o que se mostrou sobre a referida temática e nossas considerações finais.

\section{Percurso Metodológico: O Estado da Questão}

Para investigarmos o que é isso que se mostra de produções e discussões da comunidade científica brasileira sobre o tema formação inicial de professores em relação à Física Moderna e Contemporânea, realizamos como metodologia de pesquisa e análise, o Estado da Questão. Essa forma de realizar a investigação busca subsidiar o pesquisador quanto ao desenvolvimento inicial da sua pesquisa.

Segundo Nóbrega-Therrien e Therrien (2011), através de um levantamento bibliográfico seletivo, busca-se a compreensão crítica do panorama atual do tema a ser tratado. Essa compreensão crítica auxilia o pesquisador a definir e compilar o delineamento do seu trabalho, tendo uma visão ampla e inovadora, capacitando a definir e redefinir o seu objeto de pesquisa, seu objetivo, e a delimitação do problema conforme a demanda atual científica relacionada ao seu tema. Nesse sentido, Nóbrega-Therrien e Therrien (2011) ressaltam que

Partindo da apresentação dos caminhos e das conclusões anteriormente registrados por outros estudiosos ou pelo próprio estudante/pesquisador (quando se tratar de um tema já investigado por ele, por exemplo, em um trabalho anterior de dissertação de mestrado) o pesquisador, no seu modo próprio de argumentação e de apresentação, formula sua percepção original da questão ou da problemática em foco desvelando o horizonte que pretende atingir. Dessa forma, encerra-se o texto deixando a abertura para o que vem a ser o novo, ou seja, a contribuição do trabalho sobre o tema investigado (NÓBREGA-THERRIEN; THERRIEN, 2011, p. $11)$.

Os referidos autores destacam dois pontos como imprescindíveis para a elaboração do Estado da Questão, sendo eles o Domínio da Literatura e o Domínio Conceptual. O primeiro domínio é com relação à capacidade do estudante/pesquisador articular uma extensa 
gama de referências no desenvolvimento de análises e discussões. O segundo está relacionado não apenas na compreensão ou narração dos achados, mas na apropriação conceitual, de forma a manipular os conhecimentos relevantes para interpretar e explorar o seu tema de pesquisa, que servirá como ferramenta de análise crítica na sustentação de seus argumentos.

Nessa perspectiva, compreendemos que o Estado da Questão vai além da Revisão da Literatura, pois auxiliará o processo de delineamento de uma pesquisa e ao mesmo tempo possibilitará ao estudante/pesquisador habilidades para identificar e definir seus referenciais e categorias, as quais se tornam indispensáveis no processo de análise das informações e na fundamentação teórica. Assim, se trata de um mergulho profundo e específico no tema de pesquisa, com o intuito de adquirir e apropriar conhecimentos suficientes para descobrir novos caminhos importantes para a investigação.

Dessa forma, optamos por uma abordagem qualitativa, devido acreditarmos que "[...] o pesquisador exerce influência sobre a situação da pesquisa e é por ela também influenciado" (ANDRADE; HOLANDA, 2010, p.260). Além disso, o foco da atenção da pesquisa qualitativa se encontra na aspiração da compreensão dos fenômenos que somente surgem quando situados, articulados a um universo de significados, motivos, aspirações, crenças, valores e atitudes, propiciando o encontro com o novo (MINAYO, 2002). Com isso, reafirmamos de acordo com Malheiros (2011) que a pesquisa qualitativa "[...] parte do princípio de que a realidade só existe do ponto de vista da pessoa. Ou seja, o que é real é a interpretação que se faz de um fenômeno, não os fenômenos em si” (p. 188). Bicudo (2011) disserta que na pesquisa qualitativa temos o par fenômeno/percebido, em que se mostra a percepção do sujeito que investiga caracterizando essa concepção fenomenológica da realidade e do conhecimento que assumimos.

Sendo assim, com esse embasamento teórico e metodológico significamos que o desenvolvimento do Estado da Questão ocorreu da seguinte maneira: definição das fontes de consultas, seleção dos artigos e coleta das informações emergentes e, por fim a análise dessas informações. Para isso definimos como fonte de pesquisa os periódicos classificados com Qualis A1 e A2 no Qualis-Periódicos referendado pela CAPES (Coordenação de Aperfeiçoamento de Pessoal de Nível Superior) da área Ensino, quadriênio 2013-2016, como consta na Plataforma Sucupira.

Com esses critérios mencionados acima, focamos nosso olhar nas revistas brasileiras e gratuitas, porém encontramos trabalhos em português em revistas de língua espanhola. Para acrescentar na discussão dos resultados, consultamos 2 (dois) eventos nacionais da área do Ensino de Física, organizados pela Sociedade Brasileira de Física (SBF): o Simpósio Nacional de Ensino de Física (SNEF) e o Encontro de Pesquisa em Ensino de Física (EPEF).

A busca dos artigos ocorreu em um período de 10 anos, ou seja, a partir de 2009, visto que no período anterior já possui uma pesquisa bibliográfica sobre o tema de Física Moderna e Contemporânea no Ensino Médio pelas autoras Pereira e Ostermann (2009). Nessa pesquisa, as referidas autoras mostraram e discutiram o panorama geral do tema, analisando 
mais de 102 artigos publicados no Brasil e no exterior no período de 2001 a 2006. Dentre os achados da pesquisa realizada por Pereira e Ostermann (2009) apenas 6,9\% envolvem professores em serviços ou em formação inicial, sendo que "[...] esse resultado pode ser considerado baixo visto a importância do tema e a tradição da formação inicial e continuada de professores enquanto linha de pesquisa da área de ensino de ciências" (idem, p. 414).

Em relação à seleção dos artigos procedemos de duas maneiras, uma para os artigos advindos dos periódicos e outra para os artigos emergentes dos eventos. Para os artigos que faziam parte dos periódicos utilizamos na busca do título, palavras-chave ou nos resumos, os seguintes descritores: Física, Física Moderna e Física Moderna e Contemporânea. Após isso, posteriormente, era realizada uma leitura dos títulos e dos resumos procurando a relação com a temática da formação inicial de professores.

Para os artigos selecionados nos eventos da área, o SNEF e o EPEF, seguíamos para a página inicial dos eventos, navegando pelo menu no site e acessando as Atas dos mesmos. Nesse caso existem as áreas/eixos temáticas que são enviados os trabalhos. Sendo assim, o acesso ocorria nas áreas/eixos temáticos que mais se aproximavam com a Formação de Professor e Prática Docente. Com isso, realizamos os mesmos critérios de análise feitos com os artigos dos periódicos. Nesse mapeamento inicial realizado, encontramos os seguintes resultados, como mostra o Quadro 1.

Quadro 1 - Artigos emergentes na busca realizada nos periódicos.

\begin{tabular}{|c|c|c|c|}
\hline Periódicos & Autores & Código & Ano \\
\hline Ciência e Educação & Rezende Junior e Cruz & A1 & 2009 \\
\hline $\begin{array}{c}\text { Revista Brasileira de Pesquisa em } \\
\text { Educação em Ciências }\end{array}$ & Netto, Cavalcante e Ostermann & A2 & 2015 \\
\cline { 2 - 4 } & Netto, Cavalcante e Ostermann & A3 & 2019 \\
\hline $\begin{array}{c}\text { Revista Electrónica de } \\
\text { Investigación en Educación em } \\
\text { Ciencias }\end{array}$ & Monteiro, Nardi e Bastos Filho & A4 & 2012 \\
\hline
\end{tabular}

Fonte: Elaborado pelos autores, 2020.

Dessa forma, no Quadro 1 apresentamos o nome do periódico, os autores, a codificação dada e o ano em que foram encontrados os artigos. Dos eventos da área do Ensino de Física, SNEF e EPEF, após os filtros e o mapeamento realizado, foram encontrados 13 artigos, conforme explicitamos no Quadro 2.

Diante de uma primeira leitura dos artigos, fizemos uma nova seleção, uma vez que foi identificado que o foco de alguns trabalhos sobre formação inicial de professores não estava centrado na introdução de FMC no Ensino Médio. Nesses casos percebemos que o tema era apenas um conteúdo que servia como mediador no desenvolvimento da pesquisa, ou seja, não sendo relevante para o nosso objetivo da pesquisa. Dessa maneira, no Quadro 3 expomos a seleção final dos trabalhos analisados. 
Quadro 2 - Artigos emergentes na busca realizada nos eventos.

\begin{tabular}{|l|l|c|c|}
\hline Eventos & \multicolumn{1}{|c|}{ Autores } & Código & Ano \\
\hline \multirow{7}{*}{ SNEF } & Monteiro e Nardi & A5 & 2009 \\
\cline { 2 - 4 } & Potenza, Kawamura e Bechara & A6 & 2009 \\
\cline { 2 - 4 } & Sorpreso e Almeida & A7 & 2009 \\
\cline { 2 - 4 } & Aranha e Schmiedecke & A8 & 2013 \\
\cline { 2 - 4 } & Monteiro, Nardi e Bastos Filho & A9 & 2013 \\
\cline { 2 - 4 } & Fejolo e Arruda & A10 & 2013 \\
\cline { 2 - 4 } & Valentim et al & A11 & 2015 \\
\cline { 2 - 4 } & Ribeiro e Souza Filho & $\mathrm{A} 12$ & 2015 \\
\cline { 2 - 4 } & Santos et al & A13 & 2015 \\
\cline { 2 - 4 } & Gomes, Sales e Cruz & A14 & 2017 \\
\cline { 2 - 4 } & Araujo e Zago & A16 & 2017 \\
\hline \multirow{7}{*}{ EPEF } & Sorpreso, Babichak e Almeida & A17 & 2014 \\
\cline { 2 - 4 } & Silva e Carvalho & & \\
\hline
\end{tabular}

Fonte: Elaborado pelos autores, 2020.

Quadro 3 - Resultado da seleção final dos artigos emergentes.

\begin{tabular}{|l|l|}
\hline \multicolumn{1}{|c|}{ Fonte de Busca } & \multicolumn{1}{c|}{ Código } \\
\hline Periódicos & A1; A2; A3; A4 \\
\hline SNEF & A5; A6; A7; A9; A10; A12; A13; A14 \\
\hline EPEF & A16; A17 \\
\hline
\end{tabular}

Fonte: Elaborado pelos autores, 2020.

Realizada a seleção final dos artigos, o próximo passo foi analisá-los em busca da compreensão do que se apresenta nas pesquisas sobre a formação de professores para introdução de FMC no Ensino Médio nesses últimos 10 anos. Com esse objetivo, na próxima seção, discutiremos como foi feito o tratamento das informações, o que emergiu das leituras e como chegamos às categorias finais, as quais nos possibilitaram discutir aspectos importantes do cenário atual sobre formação de professores para introdução de FMC no Ensino Médio.

\section{II.1 Análise das informações emergentes}

Com uma leitura inicial das informações que emergiram no mapeamento realizado, buscamos compreender o que se mostrava das pesquisas sobre formação inicial de professores para introdução de FMC no Ensino Médio. Sendo assim, duas questões emergiram por meio de relações desses trabalhos: 1) Como ocorre e quais as consequências da formação inicial de professores para introdução de FMC no Ensino Médio? e, 2) Quais estratégias de ensino estão sendo desenvolvidas na formação inicial de professores para introdução de FMC no Ensino Médio e quais são os resultados dessas estratégias? Buscando compreender essas questões, 
foram surgindo o que viemos a chamar de características emergentes. Essas características representam fatores que apareceram com frequência durante as leituras dos artigos e da análise das informações coletadas, e que nos permitiram discutir as questões que emergiram anteriormente.

Referente à primeira pergunta, (Como ocorre e quais as consequências da formação inicial de professores para introdução de FMC no Ensino Médio?) após a análise das características emergentes, agrupamos em duas categorias iniciais, uma referente à prática do professor formador, intitulada "Prática do professor formador baseada na racionalidade técnica" e a outra referente às consequências dessa prática para a introdução de FMC no Ensino Médio que denominamos como "Consequências da racionalidade técnica na formação inicial de professores para introdução de FMC no Ensino Médio”.

Compreendendo que a primeira categoria trata da prática do professor formador baseada na racionalidade técnica, e a outra aborda as consequências dessa prática, chegamos à categoria final: Racionalidade técnica como prática do professor formador: consequências para a introdução de FMC no Ensino Médio. Essa categoria final nos possibilitou discutir como acontece a formação de professores para introdução de FMC no Ensino Médio e quais são as consequências desse modelo baseado. Esse processo está ilustrado no Quadro 4.

Quadro 4 - Processo de categorização da primeira pergunta pela análise das informações emergentes.

\begin{tabular}{|c|c|c|}
\hline \multicolumn{3}{|c|}{$\begin{array}{l}\text { Como ocorre e quais as consequências da formação inicial de professores para introdução de } \\
\text { FMC no Ensino Médio? }\end{array}$} \\
\hline Característica emergente & Categoria Inicial & Categoria Final \\
\hline $\begin{array}{l}\text { Ensino de FMC baseada no } \\
\text { formalismo matemático }\end{array}$ & \multirow{5}{*}{$\begin{array}{l}\text { Prática do professor } \\
\text { formador baseada na } \\
\text { racionalidade técnica }\end{array}$} & \multirow{8}{*}{$\begin{array}{c}\text { Racionalidade técnica como } \\
\text { prática do professor } \\
\text { formador: consequências } \\
\text { para a introdução de FMC no } \\
\text { Ensino Médio }\end{array}$} \\
\hline $\begin{array}{c}\text { Sequência didática baseada nos } \\
\text { livros didáticos }\end{array}$ & & \\
\hline Foco na resolução de exercício & & \\
\hline Exposição de conteúdo & & \\
\hline $\begin{array}{c}\text { Provas como método de } \\
\text { avaliação final }\end{array}$ & & \\
\hline $\begin{array}{c}\text { Não discutem a importância de } \\
\text { ensinar FMC }\end{array}$ & \multirow{3}{*}{$\begin{array}{l}\text { Consequências da } \\
\text { racionalidade técnica na } \\
\text { formação inicial de } \\
\text { professores para } \\
\text { introdução de FMC no } \\
\text { Ensino Médio }\end{array}$} & \\
\hline $\begin{array}{c}\text { Não permite o contato do } \\
\text { licenciando com as abordagens } \\
\text { sugeridas, pelos pesquisadores, } \\
\text { para introduzir FMC no EM }\end{array}$ & & \\
\hline $\begin{array}{l}\text { Falta de articulação, por parte do } \\
\text { licenciando, dos conteúdos }\end{array}$ & & \\
\hline
\end{tabular}




\begin{tabular}{|c|c|c|}
\hline específicos e pedagógicos & & \\
\hline Ausência de diálogo sobre as & & \\
problemáticas envolvendo a & & \\
introdução de FMC no Ensino & & \\
Médio & & \\
\hline
\end{tabular}

Fonte: Elaborado pelos autores, 2020.

Da mesma forma procedemos com a segunda pergunta "Quais estratégias de ensino estão sendo desenvolvidas na formação inicial de professores para introdução de FMC no EM e quais são os resultados dessas estratégias?". Analisamos as características emergentes, através de um processo de aproximação de significados e encontramos duas categorias iniciais, uma relacionada com a prática do professor formador, intitulada " $O$ diálogo, a interação e a pesquisa como pilares da prática do professor formador" e a outra relacionada com os resultados dessa prática denominada de "O entendimento da FMC pelo licenciando por meio da apropriação e compreensão de sua importância".

Percebemos que uma delas trata da prática do professor formador com base em uma estratégia construtivista. Significamos o construtivismo como um modelo pedagógico e epistemológico em que professor e aluno atuam em conjunto, ou seja, sujeito e objeto se constroem nesse processo de ensino e aprendizagem (BECKER, 2001). Nesse sentido, sendo um processo de construção do conhecimento que envolve a interação, diálogo e a pesquisa entre ambos os atores.

A outra categoria emerge dos frutos dessa prática do professor construtivista com a introdução da FMC no Ensino Médio, chegando a uma categoria final: "Formação inicial de professores para introdução de FMC no Ensino Médio: A interação, o diálogo e a pesquisa como pilares da prática do professor formador". Assim, essa categoria nos possibilitou discutir quais são as estratégias que estão sendo desenvolvidas na formação de professores para introdução de FMC no Ensino Médio e quais são os resultados que essas estratégias estão obtendo durante a prática. Esse processo está registrado no Quadro 5.

Quadro 5 - Processo de categorização da segunda pergunta pela análise das informações emergentes.

\begin{tabular}{|c|c|c|}
\hline \multicolumn{3}{|c|}{$\begin{array}{l}\text { Quais estratégias de ensino estão sendo desenvolvidas na formação inicial de professores } \\
\text { para introdução de FMC no Ensino Médio e quais são os resultados dessas estratégias? }\end{array}$} \\
\hline Característica emergente & Categoria Inicial & Categoria Final \\
\hline $\begin{array}{c}\text { Interação como estratégia de } \\
\text { ensino de FMC }\end{array}$ & \multirow{2}{*}{$\begin{array}{c}\text { O diálogo, a interação e a } \\
\text { pesquisa como pilares da } \\
\text { prática do professor } \\
\text { formador }\end{array}$} & \multirow{2}{*}{$\begin{array}{c}\text { Formação inicial de } \\
\text { professores para a } \\
\text { introdução de FMC no } \\
\text { Ensino Médio: A interação, }\end{array}$} \\
\hline $\begin{array}{l}\text { Diálogo e discussões em sala de } \\
\text { aula a respeito dos conceitos e }\end{array}$ & & \\
\hline
\end{tabular}




\begin{tabular}{|c|c|c|}
\hline $\begin{array}{c}\text { das estratégias de ensino que } \\
\text { envolvem a FMC }\end{array}$ & & $\begin{array}{c}\text { o diálogo e a pesquisa como } \\
\text { pilares da prática do }\end{array}$ \\
\hline $\begin{array}{c}\text { Processos investigativos como } \\
\text { estratégia de ensino envolvendo } \\
\text { temas de FMC }\end{array}$ & & professor formador \\
\hline $\begin{array}{c}\text { Problematização e desafios } \\
\text { como estratégias de ensino de } \\
\text { FMC }\end{array}$ & & \\
\hline $\begin{array}{c}\text { Apropriação e autonomia dos } \\
\text { conceitos de FMC }\end{array}$ & \multirow{4}{*}{$\begin{array}{c}\text { O entendimento da FMC } \\
\text { pelo licenciando por meio } \\
\text { da apropriação e } \\
\text { compreensão da sua } \\
\text { importância }\end{array}$} & \\
\hline $\begin{array}{l}\text { Compreensão da importância e } \\
\text { dos objetivos de ensinar FMC }\end{array}$ & & \\
\hline $\begin{array}{l}\text { Ampliação e maior clareza a } \\
\text { respeitos das abordagens, } \\
\text { sugeridas pelos pesquisadores, } \\
\text { para introduzir FMC no Ensino } \\
\text { Médio }\end{array}$ & & \\
\hline $\begin{array}{l}\text { A necessidade do licenciando } \\
\text { em reformular várias vezes seu } \\
\text { modelo explicativo }\end{array}$ & & \\
\hline
\end{tabular}

Fonte: Elaborado pelos autores, 2020.

Diante da análise das informações emergentes o que se mostra das pesquisas sobre formação inicial de professores para introdução de FMC no Ensino Médio é uma preocupação com a prática do professor formador. Dessa forma, na próxima seção discutimos, de forma mais ampla, como está acontecendo essa prática e qual a influência para a introdução da FMC na rede de ensino da Educação Básica. Além disso, explicitamos quais as estratégias de ensino que os pesquisadores da área estão desenvolvendo, quais características são consideradas importantes na prática do professor formador e os benefícios dessa ação na formação do futuro professor, e consequentemente, para a introdução desse conteúdo no Ensino Médio.

\section{Discussão dos resultados}

\section{III.1 Racionalidade técnica como prática do professor formador: consequências para a introdução de FMC no Ensino Médio}

A racionalidade técnica é uma forma de agir e pensar sobre a sociedade de forma racional e técnica, objetivando a melhor maneira de solucionar um problema. Ela foi influenciada pela consagração do Método Científico no desenvolvimento e avanços científicotecnológicos na modernidade. Para Severino (2010), esse método se apoia no Positivismo, tendo como etapas a observação dos fatos, a problematização e a formulação de uma hipótese. 
A partir disso, a ciência e a técnica são transformadas em forças produtivas em detrimento dos interesses econômicos "[...] a técnica serviu de base para a indústria, para revolução industrial, o que ampliou, sobremaneira, o poder do homem em manipular a natureza" (SEVERINO, 2010, p.105).

Nesse mesmo sentido Habermas (1968) considera que a dominação do homem cada vez mais eficaz da natureza, em detrimento do método científico, proporcionou conceitos e instrumentos para a dominação do homem sobre os homens. Para o referido autor a racionalidade, uma vez alinhada aos sistemas produtivos e econômicos, passa a exercer um papel de dominação política. As instituições escolhem quais os problemas a serem resolvidos, quais as melhores técnicas para solucionar os problemas na intenção de atingir um objetivo específico de interesses das classes dominantes.

Determinados fins e interesses da dominação não são outorgados à técnica apenas posteriormente e a partir de fora - insere-se já na própria construção do aparelho técnico; a técnica é em cada caso, um projeto histórico-social, nele se projeta o que uma sociedade e os interesses nelas dominantes pensam fazer com os homens e com as coisas. Um tal fim de dominação é material e, neste sentido, pertence a própria forma de razão técnica (HABERMAS, 1968, p. 47).

Nesse cenário de grande destaque à ciência e aos interesses econômicas, a racionalidade técnica ganhou espaço em diversos setores institucionais, sendo a educação uma delas. Em busca cada vez mais de um crescimento econômico, a educação passa a concentrar seus esforços na formação de profissionais técnicos com a intenção de qualificar a mão de obra para o desenvolvimento econômico. Esse interesse massivo na formação técnica do trabalhador desenvolve uma cultura de formação profissional baseada na racionalidade técnica que se estende também para os cursos de licenciaturas.

Segundo Tardif (2002) esse modelo predominante nos cursos de formação de professores porta algumas características negativas para educação, como: considerar o professor como técnico que aplica conhecimentos produzidos por outros; não relacionar os conteúdos específicos com os pedagógicos e muito menos aproximar a teoria com a prática real vivida pelos professores; tratar os alunos como espíritos virgens, ensinando-lhes a reproduzir os conhecimentos transmitidos em sala de aula. Slonski, Rocha e Maestrelli (2017), em sua revisão teórica sobre o tema, identificam sete características da racionalidade técnica na ação pedagógica docente:

[...] dicotomia da unidade teoria/ prática na docência; o professor como um técnico consumidor de teorias elou metodologias acadêmicas; o professor que não possui saberes e portanto não é produtor de conhecimentos; o professor que não é capaz de conceber com rigor novas metodologias de ensino ou a produção curricular; o professor como um agente isolado em um imediatismo de práticas mecânicas ou técnicas, com uma prática de ensino fortemente conteudista e acrítica; o processo de ensino e aprendizagem reduzido ao conteúdo escolar disciplinar, não abordando 
contextos sociopolíticos mais amplos e, finalmente, o professor sem plena autonomia sobre sua prática (SLONSKI; ROCHA; MAESTRELLI, 2017, p. 7).

A formação de professores para introdução de $\mathrm{FMC}$, não foge dessa cultura da racionalidade técnica, pelo contrário, a prática dos professores formadores tem apresentado algumas características desse modelo. Um indicativo dessa tendência é o fato das aulas de FMC nos cursos de licenciatura em Física serem pautadas com base apenas no formalismo matemático (REZENDE JUNIOR; CRUZ, 2009; MONTEIRO; NARDI, 2009; MONTEIRO; NARDI; BASTOS FILHO, 2013). Segundo essas pesquisas os professores e futuros professores recorrem com grande frequência ao nível de dificuldade matemática como fator que impossibilitaria a introdução de tópicos de FMC no Ensino Médio, ou seja, reproduzindo a forma que lhes foi ensinado durante seu processo formativo. Em concordância com o apego à Matemática na prática dos professores formadores, a racionalidade técnica, apresentada na formação inicial, também se baseia na exposição de conteúdo contido nos livros didáticos, este, que serve como fonte exclusiva na programação de ensino do professor formador, foco na resolução de exercícios e provas como método final de avaliação (MONTEIRO; NARDI; BASTOS FILHO, 2013; MONTEIRO; NARDI; BASTOS FILHO, 2012; MONTEIRO; NARDI 2009).

Diante dessas práticas positivistas dos professores formadores, ou seja, o foco no formalismo matemático, o empirismo, a avaliação pontual, o que se entende é que os futuros professores em seus percursos formativos não são incentivados a debater e a pensar sobre a importância da FMC na Educação Básica. Ressaltamos, que mesmo quando há algum interesse por parte dos estudantes, esses não possuem capacidades necessárias para trabalharem a FMC no Ensino Médio, pois as abordagens de ensino utilizadas pelos professores formadores, não desenvolvem autonomia para que seja possível a transposição do conteúdo para a Educação Básica. Dessa forma, os professores e futuros professores enxergam como inviável, ou nem consideram introduzir a FMC nesse nível de ensino, como afirmam Monteiro, Nardi e Bastos Filho (2013), Monteiro, Nardi e Bastos Filho (2012) e Monteiro e Nardi (2009).

A formação inicial de professores abordando o ensino de FMC através de modelos metodológicos tradicionais, não concede importância ao tema, visto que a ênfase será somente no conteúdo e não em sua aplicabilidade, seja cotidiana ou no contexto de sala de aula. Muitas dessas práticas conservadoras possuem um caráter de reprodução e são sustentadas por crenças epistemológicas empiristas ou aprioristas (BECKER, 2009). Dessa maneira, impossibilitando a discussão e a compreensão das diferenças e dos objetivos de ensinar FMC no Ensino Médio, conforme apontado por Rezende Junior e Cruz (2009)

[...] a mera tentativa de enquadrar os temas de FMC em moldes didáticometodológicos tradicionais contribuirá apenas para adicionar temas diferentes de Física, sem, contudo, tocar na parte mais sensivel que é a necessidade de redefinir o objeto a ser estudado. Isso implica rever não só o que ensinar, mas também a 
concepção de Ensino de Ciência e de Ciência [...] (REZENDE JUNIOR; CRUZ, 2009, p. 310).

Monteiro e Nardi (2009) corroboram com essa ideia ao referir sobre o ensino de Física Quântica.

\footnotetext{
A perspectiva de exposição da Física Quântica parece não satisfazer os licenciandos em termos de contribuição para um entendimento ontológico $e$ epistemológico da FMC, bem como questões relacionadas com a ciência enquanto uma construção social que incorpora os mais diversos valores culturais, politicos, econômicos e outros (MONTEIRO e NARDI, 2009, p. 7).
}

As marcas da racionalidade técnica na introdução de FMC na Educação Básica são potencializadas uma vez que as disciplinas específicas que abordam esse conteúdo são fragmentadas das disciplinas pedagógicas. Assim, essas acabam não dando o subsídio necessário para que os futuros professores possam compreender as várias formas de se abordar o tema em sala de aula e perceber, conforme apontado por Rezende Junior e Cruz (2009), os objetivos a serem alcançados ao ensinar FMC.

Tendo em vista que o ensino de FMC além de ser conceitualmente diferente do que professores e alunos estão acostumados a trabalharem em sala de aula, está intimamente ligado com desenvolvimento da ciência e da tecnologia, como também é responsável por formar um cidadão capaz de atuar e compreender o mundo atual no qual ele vive (TERRAZAN, 1992). Como percebemos há indícios que a prática do professor formador não está contribuindo de forma desejada para a introdução da FMC na Educação Básica. Monteiro, Nardi e Bastos Filho (2013) alertam sobre essa situação crítica, uma vez que as necessidades formativas dos futuros professores, sugeridas pelas pesquisas e documentos oficiais, estão sendo desconsideradas pelos professores formadores.

\section{III.2 Formação inicial de professores para a introdução de FMC no EM: A interação, o diálogo e a pesquisa como pilares da prática do professor formador}

Percebemos com a análise realizada que os pesquisadores estão priorizando o desenvolvimento de atividades de FMC que possam contribuir de alguma forma para que os egressos dos cursos de licenciatura estejam profissionalmente conscientes e preparados para introduzir esses temas na Educação Básica. A interação e diálogo entre os licenciandos durante o processo de ensino e aprendizagem são fatores que se destacam nos artigos e trabalhos analisados.

Com isso, compreendemos que essas características estão ligadas a concepções construtivistas. Solé e Coll (2009) explicitam que o construtivismo pode ser considerado como um referencial explicativo vinculado a função social e socializadora da educação, integra contribuições diversas cujo denominador comum é constituído em torno dos princípios que o regem. Nesse sentido, características como, interação e diálogo, são 
consideradas pilares da Teoria Sociocultural de Vygotsky, a qual o referido teórico intitulou por nível de desenvolvimento potencial. Nesse nível, o estado de desenvolvimento ainda não foi estabelecido pelo aluno, mas o mesmo tem o potencial de desenvolver diante da interação com outro sujeito (colegas ou professores) mais capaz. De acordo com Oliveira (2003) o nível de desenvolvimento potencial

[...] é fundamental na teoria de Vygotsky porque ele atribui a importância extrema à interação social no processo de construção das funções psicológicas humanas. $O$ desenvolvimento individual se dá num ambiente social determinado e a relação com o outro, nas diversas esferas e niveis da atividade humana, é essencial para o processo de construção do ser psicológico individual (OLIVEIRA, 2003, p. 60).

Da mesma forma, considerado imprescindível em suas obras, para Freire (1970) é através do diálogo que pronunciamos e modificamos o mundo: "Existir, humanamente, é pronunciar o mundo, é modificá-lo. O mundo pronunciado, por sua vez, se volta problematizado aos sujeitos pronunciantes, a exigir deles novo pronunciar" (FREIRE, 1970, p. 44). Os sujeitos envolvidos (licenciandos) nesse contexto se encontram em constante movimento de reformulação de seus modelos explicativos, aprimorando-os e modificando-os à medida que o estado problematizador, que surge através das interações e diálogos, os exige comunicar com os seus parceiros na busca da compreensão do fenômeno. Essas práticas, propiciadas pelo posicionamento do professor formador, em sala de aula, possibilitam a apropriação e autonomia do licenciando quanto aos conteúdos de FMC, seja estes específicos ou pedagógicos.

Assim, ressaltamos que ao trazermos como ponto principal a prática construtivista, estamos significando que o professor enxerga o estudante como parte desse processo de ensino e aprendizagem em que ambos necessitam interagir para obter algum êxito. Becker $(2009$, p. 2) explicita que com o construtivismo

[...] nada, a rigor, está pronto, acabado, e de que, especificamente, o conhecimento não é dado, em nenhuma instância, como algo terminado. Ele se constitui pela interação do Indivíduo com o meio fisico e social, com o simbolismo humano, com o mundo das relações sociais; e se constitui por força de sua ação e não por qualquer dotação prévia, na bagagem hereditária ou no meio, de tal modo que podemos afirmar que antes da ação não há psiquismo nem consciência e, muito menos, pensamento.

Potenza, Kawamura e Bechara (2009) explicitam que ao promover atividades com interações, questionamentos e provocações sobre Física Quântica, mais especificamente, do conteúdo Dualidade Onda Partícula, percebeu o fortalecimento dos conceitos básicos, dos alunos de uma disciplina do curso de Licenciatura em Física da USP, sobre o comportamento das ondas e das partículas, e também, do conceito de dualidade. Fejolo e Arruda (2013) destacam a importância da interação entre os licenciandos e dos licenciandos com o 
supervisor (professor da escola de Educação Básica) em atividades do grupo PIBID (Programa Institucional de Bolsas de Iniciação à Docência) no processo de gestão da matéria, ou seja, na escolha do conteúdo a ser trabalhado, da metodologia utilizada, métodos de avaliações e demais questões que são melhores compreendidas na prática.

Gomes, Sales e Cruz (2017) utilizando a pesquisa-ação como metodologia de pesquisa sobre as diferentes abordagens de introdução de FMC no Ensino Médio, possibilitou a investigação dos licenciandos do curso de Licenciatura em Física da USP, estimulando a discussão, a partir de bases teóricas sobre as diferenças entre linhas de pesquisa e abordagens didáticas no ensino de FMC no Ensino Médio. Os autores consideraram que os objetivos da estratégia utilizada foram alcançados, uma vez que desencadeou esse tipo de discussão.

$\mathrm{O}$ ensino por pesquisa também se mostra como alternativa de metodologia no planejamento didático, das disciplinas de formação de professores, que propiciam o contato frutífero do licenciando com o contexto pedagógico. Segundo Nova e Soares (2012), o ensino por pesquisa à docência está centrado no estudante, no qual o professor formador orienta e provoca os alunos durante suas investigações, ou seja, nessa abordagem o estudante também é encarado como um investigador. Santos et al. (2015), ao trabalhar com essa abordagem de ensino, promovendo com os licenciandos investigações sobre as concepções de alunos do Ensino Médio sobre FMC, perceberam maior clareza dos acadêmicos sobre os problemas envolvendo a introdução da FMC, e também, a conscientização sobre importância de sua incorporação no currículo do Ensino Médio. O ensino por pesquisa enxerga o licenciando como agente ativo no processo de desenvolvimento do conhecimento, possibilita a interação e o diálogo entre os sujeitos envolvidos, fazendo com que o licenciando se aproprie do tema discutido em sala de aula

Ainda com relação às interações e discussões nesse processo, é importante salientarmos que os discursos dos licenciandos possibilitam ao professor compreender os modelos explicativos usados por eles para explicação do fenômeno. Dessa forma, o professor formador pode traçar caminhos para que os licenciandos possam se apropriar da melhor forma dos conceitos envolvidos no estudo. Para Cavalcante, Netto e Ostermann (2019) essas apresentações permaneceriam camufladas em aulas tradicionais, fomentando uma compreensão rasa dos alunos sobre o fenômeno. Sorpreso, Babichk e Almeida (2010) consideram efetivo o acesso ao imaginário dos licenciandos, uma vez que este imaginário é constituído pela história anterior do estudante, assim acessá-lo, possibilita a construção de condições que provoque o deslocamento do mesmo a respeito do tema.

Como apontado na categoria anterior "Racionalidade técnica como prática do professor formador: consequências para a introdução de FMC no Ensino Médio", a fragmentação das disciplinas pedagógicas e de conteúdo específicos era uma marca da racionalidade técnica, fazendo com que os futuros professores não tivessem articulação e conhecimento sobre os objetivos e as formas de abordagem da FMC. Percebemos através dos trabalhos de Fejolo e Arruda (2013) e Sorpreso e Almeida (2009), que atividades envolvendo 
a prática pedagógica e conteúdo, no ensino de FMC na formação inicial de professores, é fundamental para que os mesmos possam mudar suas concepções sobre como, o que, e pra que ensinar esse conteúdo. Os autores ressaltam que "[...] a reflexão e o trabalho com as abordagens específicas pareceram influenciar a escolha de conteúdo a serem trabalhados" (SORPRESO e ALMEIDA, 2009, p.7), estimulando o licenciando a pensar o ensino de acordo com os objetivos de cada abordagem, tendo assim, um conhecimento mais amplo do que se pretende ser alcançado com o ensino de FMC.

Significamos que a proposição de atividades nas disciplinas dos cursos de licenciatura em Física que permitam aos sujeitos interagirem entre si em constante diálogos e questionamentos, demonstra atingir resultados significativos em relação a introdução da FMC no Ensino Médio. Visto que esses pontos contribuem tanto na compreensão dos conceitos, quanto para possibilitar a conscientização a respeito das necessidades e dificuldades da introdução da FMC no Ensino Médio.

\section{Considerações finais}

Quando se fala na formação de professores para introdução de FMC no Ensino Médio, o que se mostra é uma preocupação com a prática do professor formador. Segundo Tardif (2002) e Schon (2000) a racionalidade técnica é a prática hegemônica nos cursos de Licenciatura das universidades. Para os autores esse modelo não supre as necessidades profissionais formativas de um professor consideradas indispensáveis nas pesquisas atuais.

Na formação de professores para introdução de FMC no Ensino Médio, podemos ver que de fato a racionalidade técnica não proporciona ao licenciando um ambiente de ensino e aprendizagem, no qual os estudantes possam se apropriar e adquirir autonomia em relação a essa Física. O seu caráter tecnicista, não só impede a compreensão dos conceitos físicos envolvidos, mas também reduzem a relação que esse conteúdo tem com as disciplinas pedagógicas e o real contexto da prática docente.

Nesse sentido, as formações dos licenciados em Física propiciam professores inseguros quanto aos conteúdos relacionados à FMC. Se seguirmos essa lógica de aula, há uma desconsideração referente à participação, o diálogo e a interação do licenciando no seu processo de desenvolvimento intelectual. Com isso, não é aberto espaço para os estudantes debaterem a respeito de como a FMC pode ser abordada na Educação Básica. Se consideramos a importância e as dificuldades de introduzir a FMC no Ensino Médio, o contato com as abordagens construtivistas, enquanto modelos epistemológico e pedagógico, uma melhor apropriação do licenciando em relação ao conteúdo e a prática de ensino em sala de aula, se mostram indispensáveis.

Por outro lado, percebemos que com a investigação realizada que os professores formadores estão trilhando um caminho que possibilite uma formação mais dialógica, interacionista e investigativa. Características que promovem uma formação de professores que consiga atender à demanda necessária de um profissional apto a trabalhar com a FMC no 
Ensino Médio. Essas atividades permitem um maior engajamento do licenciando, proporcionando um espaço significativo, para que ao fim da sua formação tenha autonomia e propriedade conceitual. Além disso, incentiva o debate sobre a importância da FMC na Educação Básica, identifica as potencialidades e dificuldades encontradas.

No entanto, com a realização do Estado da Questão, ainda emergem questões para serem investigadas em futuras pesquisas, como: Como o currículo influência na prática do professor formador? Quais são os entendimentos do professor formador sobre a importância do ensino da FMC para a inserção no Ensino Médio?

Por meio desse contexto apresentado e das questões que emergem, ressaltando a importância de buscar caminhos para que a prática do professor formador possibilite uma formação plural do licenciando, que pretendemos contribuir com pesquisas futuras a respeito do tema. E com isso argumentamos que a prática do professor formador baseadas em concepções construtivistas, por meio da interação, do diálogo e a da investigação apresenta como potencial de suprir necessidades consideradas fundamentais no processo formativo do professor para introdução de FMC no Ensino Médio.

\section{Referências}

ANDRADE, C. C.; HOLANDA, A. F. Apontamentos sobre pesquisa qualitativa e pesquisa empírico-fenomenológica. Estudos de Psicologia (Campinas), v. 27, n. 2, p. 259-268, jun. 2010 .

BECKER, F. O que é construtivismo? 2009. Disponível em:

$<$ https://edisciplinas.usp.br/pluginfile.php/301477/mod_resource/content/0/Texto_07.pdf $>$.

Acesso em: 18 jun. 2020.

BECKER, F. Educação e Construção do Conhecimento. Porto Alegre: Artmed, 2001.

BICUDO, M. A. V. Pesquisa qualitativa segundo a visão fenomenológica. São Paulo: Cortez, 2011.

FEJOLO, T. B.; ARRUDA, S. DE M. A gestão da matéria no ensino de física moderna e a formação de professores. In: SIMPÓSIO NACIONAL DE ENSINO DE FÍSICA, XX, 2013, São Paulo. Atas... p. 1-8.

FREIRE, P. Pedagogia do Oprimido. 17. ed. Rio de Janeiro: Paz e Terra, 1970. 107 p.

GOMES, G. S.; SALES, N. L.; CRUZ, E. Site física moderna contemporânea nas escolas Da pesquisa à formação inicial de professores. In: SIMPÓSIO NACIONAL DE ENSINO DE FÍSICA, XXII, 2017, São Carlos. Atas... p. 1-8. 
HABERMAS, J. Técnica e ciência como ideologia. Tradução: Artur Morão. 1. ed. Lisboa: Edições 70, 1968. 149 p.

MAlheiros, B. T. Metodologia da Pesquisa em Educação. 2. ed. Rio de Janeiro: LTC, 2011. $254 \mathrm{p}$.

MONTEIRO, M. A.; NARDI, R. A Física Moderna e Contemporânea no Ensino Médio e a Formação de Professores: racionalidade técnica ou racionalidade comunicativa?. In: SIMPÓSIO NACIONAL DE ENSINO DE FÍSICA, XVIII, Vitória, ES. Atas... p. 1- 10.

MONTEIRO, M. A.; NARDI, R.; BASTOS FILHO, J. B. A sistemática incompreensão da teoria quântica e as dificuldades dos professores na introdução da Física Moderna e Contemporânea no Ensino Médio. Ciência \& Educação (Bauru), v. 15, n. 3, p. 557-580, 2009.

MONTEIRO, M. A.; NARDI, R.; BASTOS FILHO, J. B. Física Moderna e Contemporânea no ensino médio e a formação de professores: desencontros com a ação comunicativa e a ação dialógica emancipatória. Revista Electrónica de Investigacion en Educación, Argentina, v. 8, n. 1, p. 1-13, 2012.

MONTEIRO, M. A.; NARDI, R.; BASTOS FILHO, J. B. Impedimentos para alguns professores da educação básica introduzirem a física moderna e contemporânea em suas programações de ensino: Desencontros entre as diretrizes formativas e o contexto da atuação dos professores. In: SIMPÓSIO NACIONAL DE ENSINO DE FÍSICA, XX, São Paulo. p. 18.

MINAYO, M. C. DE S. Pesquisa Social: Teoria, Método e Criatividade. 21 ed. Petrópolis RJ: Editora Vozes, 2002. 80 p.

NETTO, J. DA S.; CAVAlCANTI, C. J. DE H.; OSTERMANN, F. Dificuldades e Estratégias para Compreensão do Conceito de Emaranhamento Quântico: Um Estudo na Formação Inicial de Professores de Física. Revista Brasileira de Pesquisa em Educação em Ciências, p. 1-36, abr. 2019.

NETTO, J. DA S.; CAVALCANTI, C. J. DE H.; OSTERMANN, F. Estratégias discursivas adotadas por professores em formação na compreensão do fenômeno da complementaridade em atividades didáticas mediadas pelo interferômetro virtual de Mach-Zehnder. Revista Brasileira de Pesquisa em Educação em Ciências, v. 15, n. 2, p. 293-320, jul. 2015. 
NÓBREGA-THERRIEN, S. M.; THERRIEN, J. Trabalhos Científicos e o Estado da Questão: Reflexões teórico-metodológico. Estudos em Avaliação Educacional, v. 15, n. 30, p. 5-16 jul.-dez. 2004.

NOVA, C. C.; SOARES, S. R. A relação entre ensino e pesquisa na formação inicial de professores, na visão de docentes universitários. Revista Educação e Emancipação, São Luís, v. 5, n. 2, p. 83-105, jul/dez. 2012.

OLIVEIRA, M. K. VYGOTSKY: Aprendizado e desenvolvimento. Um processo sóciohistórico. 4. ed. São Paulo: Editora Scipione, 2003. 111p.

PEREIRA, A. P.; OSTERMANN, F. Sobre o ensino de física moderna e contemporânea: Uma revisão da produção acadêmica recente. Investigações em Ensino de Ciências, v. 14, n. 3, p. 393-420, 2009.

POTENZA, B. G. G.; KAWAMURA, M. R. D.; BECHARA, M. J. A dualidade ondapartícula através de atividades na formação inicial de professores. In: SIMPÓSIO NACIONAL DE ENSINO DE FÍSICA, XVIII, 2009, Vitória. Atas... p. 1-13.

REZENDE JUNIOR, M. F.; CRUZ, F. F. DE S. Física moderna e contemporânea na formação de licenciandos em física: necessidades, conflitos e perspectivas. Ciência \& Educação, Bauru, v. 15, n. 2, p. 305-321, 2009.

RIBEIRO, A. V.; SOUZA FILHO, M. P. Transposição didática, sequência didática e avaliação formativa: Elementos para subsidiar a prática docente de bolsistas do PIBID sobre a nanotecnologia. In: SIMPÓSIO NACIONAL DE ENSINO DE FÍSICA, XXI, 2015, Uberlândia, MG. Atas... p. 1-8.

SANTOS, A. A. M. et al. Física moderna e contemporânea: Relato de atividade de pesquisa como prática pedágica na formação inicial de professores. In: SIMPÓSIO NACIONAL DE ENSINO DE FÍSICA, XXI, 2015, Uberlândia. Atas... p. 1-8.

SCHON, D. A. Educando o profissional reflexivo: Um novo design para o ensino e aprendizagem. Tradução: Roberto Cataldo Costa. Porto Alegre: Artmed, 2000. 256p.

SEVErinO, A. J. Metodologia do Trabalho Científico. São Paulo: Cortez Editora, 2010. $304 p$. 
SLONSKI, G. T.; ROCHA, A. L. F.; MAESTRELLI, S. R. P. A racionalidade técnica na ação pedagógica do professor. In: ENCONTRO NACIONAL DE PESQUISA EM EDUCAÇÃO EM CIÊNCIAS, XI, 2017, Florianópolis. Atas... p. 1-9.

SOLÉ, I; COLL, C. Os professores e a concepção construtivista. In: COLL, C. et al. O construtivismo na sala de aula. 6. ed. São Paulo: Ática, 2009.

SORPRESO, T. P.; ALMEIDA, M. J. P. M. Elaboração de episódios de ensino tratando da questão nuclear: Relações entre abordagens e conteúdo. In: SIMPÓSIO NACIONAL DE ENSINO DE FÍSICA, XVIII, 2009, Vitória. Atas... p. 1-12.

SORPRESO, T. P.; BABICHAK, C. C.; ALMEIDA, M. J. P. M. Condições de produção iniciais de estudantes de licenciatura sobre a física moderna e contemporânea. In: ENCONTRO DE PESQUISA EM ENSINO DE FÍSICA, XII, 2010, Águas de Lindóia. Atas... p. 1-12.

TARDIF, M. Saberes Docentes e Formação de Professores. 4. ed. Petrópolis: Editora Vozes, 2002. 325p.

TERRAZZAN, E. A. A inserção da física moderna e contemporânea no ensino de Física na escola de 20 grau. Caderno Brasileiro do Ensino de Física, Florianópolis, v. 9, n. 3, p. 209214, dez. 1992.

WATANABE, G. et al. Os aceleradores de partículas em aulas de física: Dificuldades encontradas por professores na elaboração de propostas. In: ENCONTRO DE PESQUISA EM ENSINO DE FÍSICA, XII, 2010, Águas de Lindóia. Atas... p. 1-12. 